\title{
Research on the Source Explanation and Measurement of Economic Performance the Enterprises Implement Green Production---Analysis Based on Enterprises Value Net
}

\author{
Huabai Bu \\ Hengyang Normal University, Hengyang, Hunan 421008, China \\ $\&$ \\ Business School, Central South University, Changsha, Hunan 410083, China \\ Shizhen $\mathrm{Bu}$ \\ Hengyang Normal University, Hengyang, Hunan 421008, China \\ Yang Gao \\ Business School, Central South University, Changsha, Hunan 410083, China
}

\begin{abstract}
Foundation projects: medium-term outcomes for project supported by Hunan Provincial Natural Science Foundation of China (10JJ3098); medium-term outcomes for project supported by Soft Science Foundation of Hunan Provincial Science \& Technology Department (2009KZ3096); medium-term outcomes for project supported by Scientific Research Foundation of Hunan Provincial Education Department of China (09C192).
\end{abstract}

\begin{abstract}
In the analyzing view of enterprise value net, this paper explains the resources of economic performance of enterprises implementing green production taking green income and green cost structure from the enterprises implementing the production operations. This article also measures and quantifies the resources to clarify the strategic thinking misunderstanding well and explicit the green cost and green income structure of enterprises implementing green production, which may provide the theoretical support and method for enterprises implementing green production.
\end{abstract}

Keywords: Implementing green production, Economic performance, Resource explanation, Measurement

\section{Introduction}

On May 8th, 2010, vice premier Li Keqiang made a speech named $<$ Driving the green development to promote sound recovery and sustained development of the world economy $>$ at the opening of international cooperation conference about green economy and coping climatic change. He held the opinion that "It has been an important trend to develop green economy in the present world and developing green industry is an important action to promote the economic structural adjustment. Developing green economy not only promote energy saving and emission reduction but also make use of resources, enlarge market demand and afford new employment effectively, which is an important connection of protecting environment and developing economies". However, according to the empirical investigation by our research group, the physical situation is just against the high attention of society and government. Now, one aspect is that many Chinese enterprises still rested on the lower level understanding such as improving the corporate image, building up business ethics view, another way to advertise and so on, even some people think that the economic efficiency of commercial enterprises is opposite to the green development and have many strategic thinking of the errors; another aspect is that the supporting theories and methods of the associated green decisions are lacked in the aspect of tactical decision, therefore, researching on the problems of the enterprises implementing green production has many important academic and practical significances. Referring to the literatures it is found that theory horizon has made many valuable explorations and achieved some research results, however, the research literatures about explaining and measuring the economic performance of enterprises based on the multiple green income and green cost structure of green production implemented by enterprises are lacked, researching on which is very important, because explicit green income and green cost structure of green production of enterprises are helpful for clarifying the strategic thinking of errors of enterprises implementing green production, which is helpful for affording the supporting theories and methods to deal with the decision aspect of the relationship between economic benefits and green production. Therefore, this paper will discuss these theory questions in the view of the analysis of enterprise Value Net.

\section{Analysis of trebling green income resources of enterprises implementing green production}

For analyzing the green income of green production of enterprises, it is localized if we only analyze the green income of enterprise in the view of enterprise Value Net, because the enterprise is always operated in some Value 
Net relation, which includes many economic entities or stakeholders such as consumers, suppliers, distributors, banks, governmental agencies, non-governmental entities, competitors, research institutes and so on and also involves the enterprise survival environment and so on in the view of system. So the green income of enterprises implementing green production is trebling, namely economic green income of enterprises, green income of other social stakeholders and green income of environment, whose specific resources are analyzed as follows:

\subsection{Green benefit brought to the enterprise own by it implementing green product}

Firstly, the green income comes from saving energy and lowering energy consumption. Saving energy and lowering energy consumption is the basic requirement for enterprise implementing green production and the important way to develop Low Carbon Economy. There are many methods and techniques to save energy and lower energy consumption for enterprise carrying through green production, such as choosing raw and processed materials for products development with reason in the supply chain, purchasing saving production equipments, designing productive technologies reasonably, managing energy strictly et al, which all can achieve the aim to save energy and lower energy consumption. We suppose that $\mathrm{I}_{1,1}$ denotes the relative green income acquired because of saving energy and lowering energy consumption by enterprise implementing green production, $\square E_{i}$ denotes the quantitative difference of the ith energy consumed by unit product before and after implementing green product by enterprises, $\Delta R_{j}$ is the quantitative difference of the jth energy consumed by unit product before and after implementing green product by enterprises, $\mathrm{N}$ is the products' quantity of enterprises, $P_{E i}$ is the unit price of purchasing the ith energy and $\mathrm{P}_{\mathrm{Rj}}$ is the unit price of purchasing the jth energy, so:

$$
I_{1,1}=\sum_{i=1}^{n} N \bullet P_{E i} \Delta E_{i}+\sum_{j=1}^{m} N \bullet P_{R j} \bullet \Delta R_{j} \quad(\mathrm{i}=1,2,3, \ldots \ldots, \mathrm{n} ; \mathrm{j}=1,2,3, \ldots, \mathrm{m})
$$

Secondly, the green income comes from reducing pollutant emissions. If the enterprise implement green production, it is required to reduce pollutant emissions and the reduction of pollutant emissions may bring the two aspects of green income: (1) the green income $\mathrm{I}_{1,2}$ is the financial aid from the government because the enterprise implement green production project; (2) the overhead charges $\mathrm{I}_{1,3}$ are saved because the enterprise implement green production project. It is supposed that $\mathrm{I}_{1,3}$ are the overhead charges saved because of enterprise implementing green production, $\Delta L_{i}$ is the quantitative difference of managing the ith pollution before and after the enterprise implementing green production, $C_{F} i$ is the unit overhead charge of producing the ith pollution when the enterprise implements green production, so the saved overhead charges because of implementing green production:

$$
I_{1,3}=\sum_{i=1}^{n} \Delta L_{i} \bullet C_{F} i \quad(\mathrm{i}=1,2,3, \ldots \ldots, \mathrm{n})
$$

Thirdly, the green income comes from the recycle and reuse of resources and productions. It is supposed that $\mathrm{I}_{1,3}$ is the cost saving because of the recycle of resources (Yuan), $\mathrm{V}_{\mathrm{Ri}}$ is the unit price of the ith resource after being dealt with (Yuan/Kilogram), $\mathrm{C}_{\mathrm{Ri}}$ is the fee for the recycle and reuse of the ith resource (Yuan/Kilogram), LRi is the unit amount of recycle for the ith resources (Kilogram), so:

$$
I_{1,4}=\sum_{i=1}^{n}\left(V_{R i}-C_{R i}\right) \bullet L_{R i} \quad(\mathrm{i}=1,2,3, \ldots \ldots, \mathrm{n})
$$

Meanwhile, if the enterprise implements green production, it is required that the products have to be recycled and reused, which not only brings to considerable financing income but also improves the corporate image, enhances customer recognition to the products, improves the market competition of enterprises, increases their own intangible green benefit. We suppose that $\mathrm{I}_{1,5}$ is the green income from the recycle and reuse of enterprises' products, $\mathrm{P}_{\mathrm{Ri}}$ is the unit value of recycle and reuse of component I, CRi is the green cost of unit recycle and reuse of component $I, L_{R i}$ is the amount of the recycle and reuse of component $I$, so the green income of the recycle and reuse of enterprises' production is expressed as follows:

$$
I_{1,5}=\sum_{i=1}^{n}\left(P_{R i}-C_{R i}\right) \bullet L_{R i} \quad(\mathrm{i}=1,2,3, \ldots \ldots, \mathrm{n})
$$

2.2 Green benefit brought to the society by enterprises implementing green production

It is supposed that $\mathrm{I}_{2,1}$ is the green income brought resulting from the improvement of laborers' health because of enterprises implementing green production, $\mathrm{P}_{0}$ is the amount of laborer, $\alpha_{i}$ is the purifying rate after implementing green production, $\gamma_{0 i}$ is the discharge of one special pollutant of the enterprise when it implement green production, $\gamma_{i}$ is the total amount of one pollutant in the environment, $\mathrm{m}$ is the kind number 
of pollutants, $\Delta P_{\alpha}$ is the quantitative difference of morbidity before and after implementing green production, $b_{p}$ is the life value of one person for one year(Yuan/Year), T0, T are separately the days of infecting with a disease and working days of one year, $\mathrm{C}$ are the hospitalization costs paid by the suffer in one year (Yuan/ Person*Year), $\Delta P_{\beta}$ is the variety of death rate before and after implementing green production, $\mathrm{Bp}$ is the life value of one person in the end of the th year(Yuan/Year). It can be estimated as follows:

$$
I_{2,1}=P_{0} \sum_{i=1}^{m} \frac{\alpha_{i} \gamma_{0 i}}{\gamma_{i}}\left[\Delta P_{\alpha}\left(b_{p} \bullet \frac{T_{0}}{T}+C\right)+\Delta P_{\beta} \bullet B_{P}\right] \quad(\mathrm{i}=1,2,3, \ldots \ldots, \mathrm{m})
$$

\subsection{Green income brought to the environment by enterprises implementing green production}

The green benefit brought to the environment by the enterprise implementing green production mainly represents in two aspects: (1) the improvement of environment bring the increase of flora and fauna and the increase of flora would bring green benefit; (2) the improvement of environment would decrease environmental hazards and the decrease of environmental hazards would bring green benefit.

The release of harmful substances would decrease because the enterprise implements green production, which may improve the environment around the enterprise and this improvement will bring ecological-economical benefit because of the increase of flora and fauna. It is supposed that $\mathrm{I}_{3,1}$ is the ecological-economical benefit brought by the increase of flora and fauna because of enterprise implementing green production, $\mathrm{N}_{\mathrm{o}}$ is amount of one special flora or fauna (head, spit), By is the life value of one special flora or fauna (Yuan/head, spit). The resting signs are the same as the above.

$$
I_{3,1}=\sum^{n} N_{j} B_{j} \quad(\mathrm{j}=1,2,3, \ldots \ldots, \mathrm{m})
$$

The improvement of environment would dectelase environmental disasters and the loss caused by the decreasing environmental disasters can also be understood as the green benefits because of implementing green production. It is supposed that $\mathrm{I}_{3,2}$ is the ecological-economical benefit brought by the decrease of pollution, $\beta_{i}$ is the ecological area (a unit of area) affected by the decreasing disasters, $\phi_{i}$ is the pollutional load coefficient, $\Delta y_{i}$ is the decrease of some zoology $(\mathrm{kg} / \mathrm{a}$ unit of area), $\mathrm{Pi}$ is the ecological price(Yuan/Head, Spit), $\mathrm{Nj}$ is the number of some flora or fauna(Head, Spit), Pj denotes the life value of some flora or fauna(Yuan/ Head, Spit). So:

$$
I_{3,2}=\sum_{i, j=1}^{n, m} \phi_{i}\left(\beta_{i} \Delta y_{i} P_{i}+N_{j} P_{j}\right) \quad(\mathrm{i}=1,2,3, \ldots \ldots, \mathrm{n} ; \mathrm{j}=1,2,3, \ldots, \mathrm{m})
$$

Environmental contamination causes damage not only to the human beings and environment but also to metalwork, dry goods, building and so on, therefore, the improvement of environment also can minish the damage of metalwork, dry goods and building, which is also brought by the enterprise implementing green production. It is supposed that $I_{3,3}$ is the substance losing resulting from the environmental contamination (Yuan/Year), $\phi_{i}$ is pollutional load coefficient, $B_{0 i}$ is the economic loss of some practicality in those years(Yuan), $i_{0}$ is the annual interest rate, $T_{0}$ is the actual service life of some practicality (Year), $T$ is the depreciable life (Year) of some practicality (Year). It can be expressed as follows:

$$
I_{3,3}=\frac{1}{T_{0}} \sum_{i=1}^{n} \phi_{i} B_{0 i}(1+i)^{T_{0}}\left(1-\frac{T_{0}}{T}\right) \quad(\mathrm{i}=1,2,3, \ldots \ldots, \mathrm{n})
$$

\section{The analysis of the sources of double green cost that enterprises implement green production}

For the analysis of green cost of enterprises' green production, it is very limited to analyze enterprises' own green cost. From the view of enterprises' Value Net, the green benefit that enterprises implement green production is double, which means enterprises' own economic green cost and social other stakeholders' green cost, whose specific analysis of sources are below:

\subsection{Green cost produced by enterprises implement green production}

Green cost produced by enterprises implement green production includes mainly the fees in the stage of green design of enterprises' products; the fees in the stage of green production of enterprises' products and the fees used for environmental management by enterprises.

Firstly, the green cost produced in the stage of green design of enterprises' products. From the view of fixed green cost, it mainly includes purchase cost, planning cost and implementation cost that enterprises invest in the task of green design and the sum of the three kinds of cost is supposed as $\mathrm{C}_{1,1}$. Discussion: the condition above means the fees of enterprises' green design in the condition that green design can be finished successfully. But because of the complexity of problems, enterprises' green design also produces scrap cost and rework cost.

The scrap cost of design proposal means for the same kind of scrapped design proposal, we suppose $\mathrm{C}_{1,2}$ means the cost lost by design scrap, $\mathrm{L}_{\mathrm{DW}}$ means the number of certain kind of scrap proposal, $\mathrm{C}_{\mathrm{HK}}$ means comparable design's green cost of the kind of design proposal, and then: 


$$
C_{1,2}=\sum_{i=1}^{n} L_{D W} \bullet C_{H K} \quad(\mathrm{i}=1,2,3, \ldots \ldots, \mathrm{n})
$$

Rework cost means the fees wasted by reworked design which is caused by the errors in the stage of design (for example: the problem of saving energy and lowering consuming). Supposed $C_{1,3}$ is rework cost, $P_{D R}$ means the cost of unit working hour of the kind of design proposal, $\mathrm{T}_{\mathrm{DR}}$ means reworking hours of certain kind of product design, and then

$$
C_{1,3}=\sum_{i=1}^{n} P_{D R} \bullet T_{D R} \quad(\mathrm{i}=1,2,3, \ldots \ldots, \mathrm{n})
$$

After the design is finished, enterprise will enter the system operation of green design stage, so this will also produce system operation cost(supposed as $\mathrm{C}_{1,4}$ ) and the total cost of system improvement and update. Suppose $\mathrm{C}_{1,5}$ represents the total cost of system improvement and update, $\mathrm{K}_{\mathrm{I}}$ means the investment needed by system improvement and update, $\mathrm{C}_{\mathrm{Ij}}$ represents the operating green cost of system improvement and update in the year of $\mathrm{j}, \mathrm{V}_{\mathrm{oo}}$ represents the value of former system in decision-making year, $\mathrm{V}_{\mathrm{nL}}$ represents the residual value of the year of $\mathrm{n}$ after system improvement and update. $\beta$ means the coefficient of production efficiency after system improvement and update, $\gamma_{j}, \gamma_{n}$ means present value coefficient. The cost of system improvement and update can be shown as follows:

$$
C_{1,5}=\frac{1}{\beta}\left(\left(K_{I}+\sum_{j=1}^{n} \gamma_{j} C_{l j}\right)-V_{00}-V_{n L} \bullet \gamma_{n}\right) \quad(\mathrm{j}=1,2,3, \ldots \ldots \mathrm{n})
$$

Secondly, related cost in the stage of enterprises' products' green production and in the stage of enterprises' components' recycle process and recycling utilization. Enterprise also produces green transform cost from the past non-green products' production model to green products' production model and we suppose this kind of green transform cost as $\mathrm{C}_{1,6}$.

With the increasing environmental pollution, many countries especially western industrial developed country put forward the idea of environmental protection that 'who pollutes, who should undertake the responsibility' through making laws, and many big companies also begin to pay attention to products' recycle process and recycling utilization. Supposed $\mathrm{C}_{1,7}$ as the cost used by enterprise for recycle process and recycling utilization, $\mathrm{P}_{\mathrm{RK}}$ as the green cost of unit recycle process and recycling utilization of the component $k, \mathrm{~L}_{\mathrm{RK}}$ as the number of recycle process and recycling utilization of the component $\mathrm{k}$. Then:

$$
C_{1,7}=\sum_{k=1}^{n} P_{R K} \bullet L_{R K} \quad(\mathrm{i}=1,2,3, \ldots \ldots, \mathrm{n})
$$

Green production requires enterprise to reduce waste emission in the process of production and try to recycle unavoidable waste. Supposed $\mathrm{C}_{1,8}$ as the cost of resource recovery and handling(Yuan), $\mathrm{P}_{\mathrm{MK}}$ as the cost of recovery and handling of resource $\mathrm{k}(\mathrm{Yuan} / \mathrm{Kg}), \mathrm{L}_{\mathrm{NK}}$ as the amount of recovery and handling of resource $\mathrm{k}(\mathrm{Kg})$. Then the cost of resource reclaims utilization is:

$$
C_{1,8}=\sum_{k=1}^{n} P_{M K} \bullet L_{M K} \quad(\mathrm{i}=1,2,3, \ldots \ldots, \mathrm{n})
$$

Thirdly, the fees used by enterprises for environmental management. Supposed $\mathrm{C}_{1,9}$ as the total cost of environmental management, $\mathrm{Li}$ as the kind i of amount of pollution manufacturing system discharges, $\mathrm{Pi}$ as the unit management cost of the kind i of pollutant. Then:

$$
C_{1,9}=\sum_{i=1}^{m} L_{i} \bullet P_{i} \quad(\mathrm{i}=1,2,3, \ldots \ldots, \mathrm{n})
$$

\section{2 other stakeholders' cost that enterprises implement green production}

Here the stakeholders mean government, research institutes and other public welfare groups. Supposed other stakeholders' cost that enterprises implement green production as $\mathrm{C}_{1,10}$. The grant of government for the enterprises who implement green production, the research and development of technology that government provides support for enterprises' green production, the fees that the government invests in the management of environmental public pollution and so on, can be understood as the cost of the government for the enterprises who implement green production. In research institutes, especially the one which engage in the research of green production of enterprises, their researchers spend a lot of time and fees on the problems of enterprises' green production and their results can serve for the green production of enterprises directly and the investment also consists of the cost of green production that enterprises implement. Besides, some social public welfare groups also may produce fees for enterprises' green production. For example, in the Annual Summit of China Green Companies hold in Chengdu, Sichuan Province, in April 2010, eight organizations including China Entrepreneur 
Club and so on jointly sponsored the public welfare project "green homeland, happy world" and the Annual Summit also contributed money to "green life organization", which are beneficial to the spread and shape of enterprises' green brand and finally are is helpful to promoting the process of green production of enterprises.

\section{Economic performance measurement of the implementation of green production in enterprises}

Suppose $\mathrm{R}$ as the green benefit that enterprises implement green production, $\mathrm{C}$ as the green cost that enterprises implement green production, and then according to the analysis before we can obtain directly:

$$
\begin{aligned}
& R=\sum_{i=1}^{n} N \bullet P_{E i} \Delta E_{i}+\sum_{j=1}^{m} N \bullet P_{R j} \bullet \Delta R_{j}+\sum_{i=1}^{n} \Delta L_{i} \bullet C_{F i}+\sum_{i=1}^{n}\left(V_{R i}-C_{R i}\right) \bullet L_{R i}+ \\
& \sum_{i=1}^{n}\left(P_{R i}-C_{R i}\right) \bullet L_{R i}+P_{0} \sum_{i=1}^{m} \frac{\alpha i \gamma_{0 i}}{\gamma_{i}}\left[\Delta P_{\alpha}\left(b_{p} \bullet \frac{T_{0}}{T}+C\right)+\Delta P_{\beta} \bullet B_{P}\right]+ \\
& \sum_{i=1}^{n} N_{j} B_{j}+\sum_{i, j=1}^{n, m} \phi_{i}\left(\alpha_{i} \Delta y_{i} P_{i}+N_{j} P_{j}\right)+\frac{1}{T_{0}} \sum_{i=1}^{n} \phi_{i} B_{0 i}(1+i)^{T_{0}}\left(1-\frac{T_{0}}{T}\right)+I_{00} \\
& C=\sum_{i=1}^{n} L_{D W} \bullet C_{H K}+\sum_{i=1}^{n} P_{D R} \bullet T_{D R}+\frac{1}{\beta}\left(\left(K_{I}+\sum_{j=1}^{n} \gamma_{j} C_{I j}\right)-V_{00}-V_{n L} \bullet \gamma_{n}\right)+ \\
& \sum_{k=1}^{n} P_{R K} \bullet L_{R K}+\sum_{k=1}^{n} P_{M K} \bullet L_{M K}+\sum_{i=1}^{m} L_{i} \bullet P_{i}+C_{00}
\end{aligned}
$$

in which $I_{00}$ and $C_{00}$ represent the sum of other green benefit and other green cost that each part of enterprises mentioned above implement green production respectively. Then we can approximately measure the total green benefit and total green cost that enterprises implement green production according to the formula above.

Suppose $\eta$ as the economic performance that enterprises implement green production, and then

$$
\eta=(\mathrm{R}-\mathrm{C}) / \mathrm{C}=(\mathrm{R} / \mathrm{C})-1
$$

From the functional formula above we can see, the economic performance function that enterprises implement green production is a complex multivariate function. According to the method of obtaining the most value of multivariate function, we can calculate out the optimal solution that enterprises implement green production under a certain constraint condition.

Discussion: Suppose $\mathrm{X}$ represents the independent variable in the total green benefit function and total green cost function that enterprise implement green production, $\mathrm{n}$ represents the numbers of all the independent variables, and then according to $\frac{\partial \eta}{\partial x_{n}}=\frac{\partial(R / C)}{\partial x_{n}}=0$ we can obtain $\mathrm{n}$ equations. If combining with other constraint conditions we can obtain the optimal production and investment model of green production in enterprises. As an empirical case, our research group carried out green cost effective and performance measurement of green production and here is the specific data as shown in the table below:

From the above table it can be found that the minimum of economic performance of these four medium-sized and small enterprises implementing green production is $25.8 \%$ and the maximum is $38.5 \%$, which also approve that the point of view "the economic benefits of enterprises are contrary to the green development" is wrong. Let us take a chemical enterprise A as an example, the performance of implementing green production is obvious greater, mainly because in the past the negative influence on the environment is comparatively large and in the background of low level carbon economy, the high level management highly value the construction of green enterprises and the extent of implementing green production is very large; while the performance of green production implemented by the thermal power factory $\mathrm{D}$ is relatively small, mainly because the strength of the government supporting the green construction is not enough, at the same time, the investment on the design cost and renovation cost of production system is too much at the beginning of reformation.

\section{Conclusions and suggestions}

In the strategy tier, enterprise must establish the operation idea of implementing green production and pay attention to foster green consciousness of staff so that they adopt advanced technology consciously to save energy and lower energy consumption and curb emissions and reduce pollution in the production management and operation activities. While enterprises do research and develop the technology of green production, they make full use of related laws and regulations about environmental protection and green production. According to their own practical situations, they make use of preferential policies about saving energy and lowering consuming our country formulated to implement green production unswervingly and promote effective and 
coordinated development between enterprises' economic benefit and green production. In the operation tier, enterprises' technology design should try their best to avoid the discharge of "three wastes" and hazardous substances and deal with them timely in overall process in order to reduce the green cost of management. They should increase the investment in technology, improve original equipment or introduce advanced equipment, save the amount of the raw materials in the course of working, reduce three waste emissions, the production of noise and harm to human health of workers so as to achieve enterprises' request of green production. Meantime, enterprises should strengthen the publicity of green education and green production in order to make people has an accurate knowledge to the effect and meanings of enterprise green production so that the concept of green production is deeply rooted in people's mind and in the whole society a good environment of green production and green consumption are formed. Of course, each enterprise should combine its own industrial characteristics to formulate suitable strategy of green production. Only in this way can enterprises increase the performance of green production and obtain competitive advantage continually and thereby ensure the sustainable and healthy development of enterprises.

\section{References}

Chen, Hongming, Li Tongming et al. (2007). On green supporting systems in enterprises. China Population, Resources and Environment. 2007, 11(1): 56 60.

Hadfield R B. (2008). Green Supply Chain: Best practices From the Fumet Industry. Annual Meeting of the Decision Sciences Institute, USA, 2008:1295-1297.

Li, Huiming, Pan, Yang and Cui, Xiaoying. (2010). The differentiation and analysis about the essence and relationship of greener form of development. The China Environment News, 2010, 6, 9.

Liu, Bin and Zhu, Qinghua. (2009). Empirical study on practices and performances of green purchasing among manufacturing enterprises. Chinese Journal of Management. 2009, 6(1): 56 62.

Liu, Wenhui. (2009). A study on green business innovation of enterprises. The doctoral dissertation of Ocean University of China, 2009, 6 .

Luan, Xiuming. (2010). Green Development should rise as the national policy. China Business Times, 2010, 4, 29.

Min H., Galle W.P. (2009). Green Purchasing Strategies: Trends and Implications. International Journal of Purchasing and Materials Management 2009, (4):10-17.

Wang, Li and Liu, Yingzong. (2009). Game analyses among the associated bodies of the enterprises' green management. Modern Management Science, 2009(5):107 108.

Yu, Dongmei. (2009). Research on the enterprises' green management based on game theory. Academic Exchange, 2009, 185(8):64 66.

Table 1. The green benefit, green cost and performance that enterprises implement green production

\begin{tabular}{|l|l|l|l|l|}
\hline $\begin{array}{l}\text { enterprise } \\
\text { category }\end{array}$ & $\begin{array}{l}\text { Chemical } \\
\text { industry A }\end{array}$ & $\begin{array}{l}\text { equipment } \\
\text { manufacturing } \\
\text { enterprise B }\end{array}$ & $\begin{array}{l}\text { lead/zinc } \\
\text { enterprise C }\end{array}$ & $\begin{array}{l}\text { steam power plant } \\
\text { D }\end{array}$ \\
\hline $\begin{array}{l}\text { Green } \\
\text { benefit(ten } \\
\text { thousand yuan) }\end{array}$ & 876.55 & 938.77 & 697.82 & 768.99 \\
\hline $\begin{array}{l}\text { Green cost(ten } \\
\text { thousand yuan) }\end{array}$ & 632.89 & 734.56 & 530.26 & 611.28 \\
\hline performance & $38.4 \%$ & $27.8 \%$ & $31.5 \%$ & $25.8 \%$ \\
\hline
\end{tabular}

